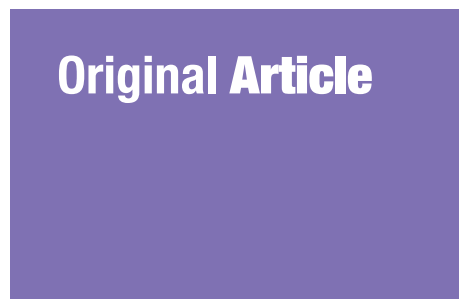

Submitted: 6 Feb 2016 Accepted: 16 Sept 2016 Online: 7 Dec 2016

\section{Radiographic Evaluation of the Status of Third Molars in Sriganganagar Population - A Digital Panoramic Study}

\author{
Sharry Goyal, Pradhuman Verma, Seetharamaiha Sunder RaJ
}

Department of Oral Medicine \& Radiology, Surendera Dental College \&

Research Institute, Sriganganagar, 335001 Rajasthan, India

To cite this article: Goyal S, Verma P, Sunder Raj S. Radiographic evaluation of the status of third molars in Sriganganagar population - A digital panoramic study. Malays J Med Sci. 2016;23(6):103-112. http://dx.doi. org/10.21315/mjms2016.23.6.11

To link to this article: http://dx.doi.org/10.21315/mjms2016.23.6.11

\title{
Abstract
}

Background: Third molar (M3) agenesis and impaction are associated with evolution, changed dietary habits, and human jaw growth. The aim of the study was to radiographically evaluate the prevalence of M3s agenesis, impacted M3s with different impaction patterns, and the approximation of Inferior Dental Canal (IDC) with impacted mandibular M3s roots among the Sriganganagar population.

Methods: The study included 700 randomly selected subjects from OPD with an age range of 25-45 years. Digital OPGs were taken for all subjects using Kodak 8oooC digital OPG machine. The M3 impaction patterns were evaluated using Winter's classification.

Results: The prevalence of subjects with at least one M3 agenesis was found to be $34.1 \%$ and with $95 \%$ confidence interval was $30.6 \%$ to $37.6 \%$. The overall M3s agenesis was $16.8 \%$ with more prevalence in the males. The patients with agenesis of one M3, two M3s, three M3s, and four M3s were $14.4 \%, 11.3 \%, 3.7 \%$ and $4.7 \%$, respectively. M3 agenesis was more in the upper jaw and on the left side. The total impacted M3s were $21.11 \%$ with more prevalence in mixed diet subjects. Mesioangular was most common impaction pattern, and notching was most prevalent IDC relationship with impacted mandibular M3s roots.

Conclusion: This study highlighted the evolutionary increasing M3 agenesis and the importance of diagnostic OPG for seeing the status of M3s in jaws.

Keywords: agenesis, impacted tooth, panoramic radiography, third molars

\section{Introduction}

The third molar (M3) of the human dentition is associated with varying coronal and radicular morphology during its formation (1). The M3 crown formation starts at 11 years of age in about $90 \%$ of the cases, and it has varying eruption period. It frequently erupts between 18 to 20 years of age (2). The M3s are believed to have once been a necessity for early human ancestors who used to break their food with jaws and hands. In addition, the nature of their food was coarse and rough that required more chewing power as compared to modern food. In modern man, there is little room for $\mathrm{M}_{3}$ to be spaced in the jaw as compared to our ancestors (3).

The M3s are the most common congenitally missing teeth that could be attributed to the evolutionary changes, systemic diseases, genetic polymorphism, teratogens, changes in the dietary habits, physical disruption or inherent defect of the dental lamina, limitation of space, and loss of induction of the underlying tissues for its formation. It can occur in an isolated fashion or a part of a syndrome (4). The frequency of M3 agenesis ranges from $14 \%$ to $51.1 \%$ (5), and it has implications for age estimation in forensic and legal matters (6). 
The impacted M3 represents incomplete eruption because of its relatively inclined position to the adjacent tooth, the ascending part of ramus or their vertical position; the eruption is hindered due to space deficiency or overlying soft tissue hindrance (7). The causes of impaction include both general and local factors. The general factors may consist of dietary habits, heredity factors, abnormality in genetic makeup, and malnutrition. The local factors include adjacent 2nd molar tooth size and position, overlying dense bone, long path of eruption, and insufficient dental arch length (8). Studies have shown that impacted mandibular M3 weakens the angle area of the mandible and makes it susceptible to fracture and late lower arch crowding $(9,10)$. The prevalence of $\mathrm{M}_{3}$ impaction ranges from $16.7 \%$ to $68.6 \%$ with no sexual predilection (9). Several methods are used to classify the impaction; the Winter's classification is one such commonly used method (11).

As the surgical removal of impacted mandibular $\mathrm{M}_{3}$ increases the risk of injury to the inferior dental canal (IDC), which may lead to nerve paresthesia, there is a need to study the relationship between roots of impacted mandibular M3s and IDC to avoid this complication (12). Anatomically, the IDC encloses the nerve within the dense bony tube, which can be seen radiographically as two parallel radiating lines representing the floor and roof of the canal, respectively (13). The reported frequency of injury to IDC associated with extraction of impacted mandibular M3s ranges from $0.6 \%$ to $5.3 \%$ (14).

Panoramic radiography is a common technique to evaluate the prevalence of M3s, their impaction status, and the proximity of the impacted mandibular M3s to IDC. Several radiographic signs like darkening of the radicular portion, lack of cortical margins, mandibular canal deviation, and deflected or narrowing of radicular portion have been associated with an increased IDC injury risk. The main advantage of panoramic radiography is its less exposure time and small biological exposure of X-rays. Moreover, the reliability of orthopantomogram (OPG) was evaluated against computed tomography (CT) images by many authors who suggested that OPG is an invaluable tool with the best cost-information ratio (15). With this background, the present study was conducted to radiographically evaluate the prevalence of M3s, status of their impaction in both jaws, and relationship of impacted mandibular M3s with IDC among the semi-urban population of Sriganganagar, a district in Rajasthan.

\section{Materials and Method}

This cross-sectional study was conducted from January, 2014 up to February, 2015 at Surendera Dental College \& Research Institute, Sriganganagar, Rajasthan, India. The study sample consisted of 700 randomly selected subjects of either sex between the age of 25 and 45 years who attended the outpatient department (OPD) of Oral Medicine and Maxillofacial Radiology.

The number of subjects included in this study was larger compared to other similar studies conducted among the Indian population, such 578 subjects by Gupta et al. (16), 290 subjects by Punjabi et al. (9), 100 subjects by Shah et al. (3), and 100 subjects by Sandhu et al. (4).

Informed and written consent was obtained for each patient. The institutional ethical committee clearance was obtained for conducting this study (SDCRI/IEC/2013/006 dated 19/12/13).

\section{Inclusion criteria}

1. Healthy subjects with no history of surgery involving posterior quadrants of both jaws.

2. Patients who were non-syndromic (Alpert Syndrome, Ectodermal dysplasia, Hunter Syndrome, etc.) and with no systemic disorder (Hyperparathyroidism, Celiac disease, Vitamin D resistant rickets, etc.).

3. No history of trauma to the jaws.

4. OPGs of all above selected patients were included in the study.

\section{Exclusion criteria}

1. Image deformity affecting M3s and IDC visualisation on OPG.

2. Patients with a history of extraction of M3s.

3. Patients with a history of orthodontic treatment.

4. Pregnant females.

\section{Method}

The detailed case history was recorded for each selected subject, and the intraoral examination was carried out in a systematic manner for the presence, absence, and partially 
Original Article | Radiographic evaluation of the status of third molars

erupted M3s by a single operator well trained with the screening procedure. The structured proforma was designed to record the details of the patient. The patients satisfying the inclusion criteria were subjected to digital panoramic radiography using Kodak $8000 \mathrm{C}$ digital OPG/ Cephalometric machine (Figure 1) following the ICRP guidelines. This was performed by a trained radiographer so as to ensure the safety of the patient and the operator. The radiographs used for the study were selected by an Oral and Maxillofacial radiologist following the exclusion and inclusion criteria. The selected radiographs were evaluated for the status of right and left maxillary and mandibular M3s, pattern of impaction, if any, and for the approximation of IDC to the root apices of mandibular impacted M3s.

\section{Radiographic interpretation}

If $\mathrm{M}_{3}$ was not erupted to its normal functional position in the plane of occlusion, it was considered impacted. The inclination of impacted M3s was evaluated by measuring the angulation between the longer axis of $\mathrm{M}_{3}$ and the adjacent second molar tooth using Winter's Classification (16) (Figures 2 and 3) as follows: 1) Vertical impaction: $10^{\circ}$ to $-10^{\circ}$; 2) Mesioangular impaction: $11^{\circ}$ to $79^{\circ}$; 3) Distoangular impaction: $-11^{\circ}$ to $-79^{\circ}$; 4) Horizontal impaction: $80^{\circ}$ to $100^{\circ}$; 5) Others: $111^{\circ}$ to $-80^{\circ}$; 6) Bucco-lingual impaction.

The classification of uncommon angulations such as 'Mesio-inverted,' Disto-inverted and Disto-Horizontal' was combined and designated as 'others'.

The radiographic approximation of root apices of mandibular-impacted M3s and IDC was evaluated and categorised as follows (16) (Figure 4):

1. Adjacent: when the root apices touched the superior border of IDC or within $2 \mathrm{~mm}$ below them.

2. Superimposed: when the IDC image was are superimposed over the root apices and appeared less radiopaque than the rest of the radicular image radiographically.

3. Notching: when the root apices show radiolucent band, break in the continuity of superior radiopaque border of IDC with narrowing.

4. Grooving: roots showing radiolucent band across and above the apices.
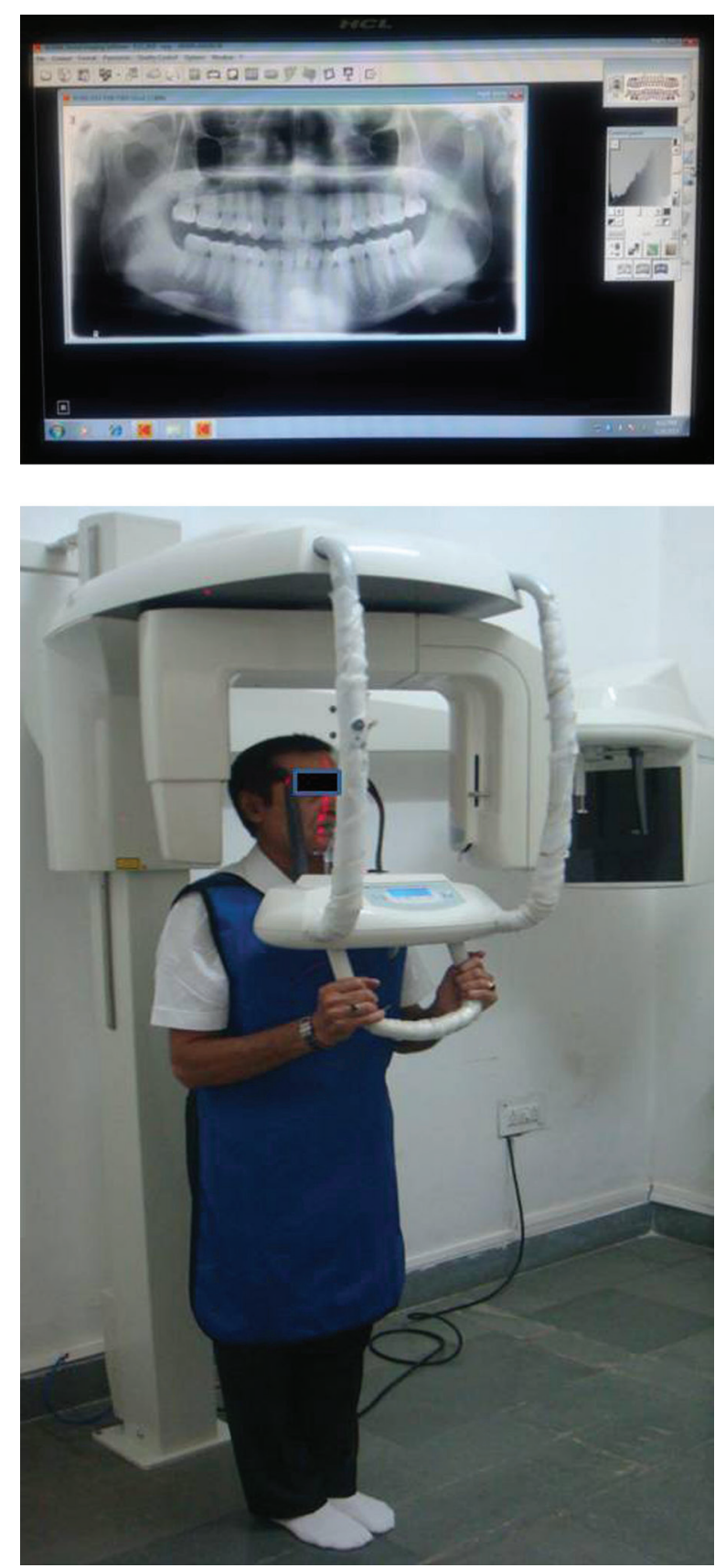

Figure 1. Digital Panoramic machine (Kodak 800oC).

5. Perforation: radiolucent band that crossed the root above the apex, and loss of both superior and inferior borders of the IDC at the crossing area and maximal constriction of the canal in the middle of the radicular portion.

6. None: the approximation between IDC and root apices cannot be assessed decisively. 
All the radiographic evaluations and measurements were independently done by two Oral \& Maxillofacial radiologists who were well trained with the screening of OPGs to reduce the inter-observer bias. The data collected was tabulated and subjected to statistical analysis using Chi-square tests by SPSS data editor software Version 20 (Microsoft Corporation Inc., Chicago, IL, USA). The inter-observer bias was also calculated using the Wilcoxon signed ranks test, and the reliability statistics were done using Cronbach's Alpha test. The level of statistical significance was set at $P<0.05$.

\section{Results}

Of the 700 subjects, $64.9 \%$ were males and $35.1 \%$ were females with an overall mean age of 32.32 (6.52) years. The diet distribution of the study showed that $36 \%$ subjects were vegetarians and $64 \%$ were on a mixed diet. The total $\mathrm{M}_{3}$ agenesis was $16.8 \%$. Out of the total 2,331 M3s present, 492 were found to be impacted.

The inter-observer bias was statistically analysed, and it was found to be insignificant. From the total sample, $34.1 \%$ had at least one third molar agenesis. The prevalence with 95\% confidence interval is $30.6 \%$ to $37.6 \%$. The distribution of subjects with agenesis reported for one M3 was $14.4 \%$, two M3s $11.3 \%$, three M3s $3.7 \%$ and for all four M3s was $4.7 \%$ (Table 1).

The total percentage of agenesis of 18,28 , 38 and 48 was reported to be $32.2 \%, 27.1 \%$, $19.6 \%$, and $21.1 \%$, respectively. Of all the M3s agenesis, 278 were found in males and 191 in females. The $P$-value between both genders and M3 agenesis was found to be insignificant for 18 , 28 and 48. In addition, the agenesis of M3s was found to be higher in maxilla in both genders (males $=171$; females $=107$ ). When statistically analysed in both genders using Chi-square tests, it was found to be insignificant $(P=0.192)$ for maxillary and significant $(P=0.006)$ for mandible (Table 2).
Table 1. Distribution of subjects with agenesis of third molars

\begin{tabular}{lcc}
$\begin{array}{l}\text { Agenesis of } \\
\text { third molars }\end{array}$ & $\begin{array}{c}\text { Number of } \\
\text { patients }\end{array}$ & Percentage \\
$\begin{array}{l}\text { All third molars } \\
\text { present }\end{array}$ & 461 & 65.9 \\
$\begin{array}{l}\text { One third molar } \\
\text { agenesis }\end{array}$ & 101 & 14.4 \\
$\begin{array}{l}\text { Two third molars } \\
\text { agenesis }\end{array}$ & 79 & 11.3 \\
$\begin{array}{l}\text { Three third molars } \\
\text { agenesis }\end{array}$ & 26 & 3.7 \\
$\begin{array}{l}\text { All are absent } \\
\text { Total }\end{array}$ & 33 & 4.7 \\
\hline
\end{tabular}

The agenesis of M3s was found to be $53.3 \%$ on the right side; $46.7 \%$ on the left side, and when statistically analysed between both the genders, it was found to insignificant for the right side $(P=0.076)$. The percentage of impacted $18,28,38$ and 48 was found to be $16.5,18.3 \%$, $32.9 \%$ and $32.3 \%$, respectively. The M3s were found to be 307 in males and 185 in females, and the $P$-value was found to be significant for 18 for both genders.

The impacted M3s were found to be more in the mixed diet subjects than the vegetarians. The correlation between the dietary pattern and impacted M3s was found to be insignificant ( $P$-value $>0.05$; Table 3 ).

The mesioangular impaction pattern of M3s (41.5\%) was found to be the most common followed by distoangular (30.1\%), vertical (18.3\%), horizontal (6.1\%), buccolingual (3.6\%), and others $(0.4 \%)$. The mesioangular was the most common pattern of impaction (53.8\%) seen in mandible and distoangular (48\%) in the maxilla (Table 3).

In the present study, notching was the most common relationship of IDC with the root apices of impacted mandibular M3s, constituting 39.6\% followed by adjacent (33.6\%), superimposed

Table 2. Distribution of agenesis of third molars

\begin{tabular}{lccccccc} 
Gender & $\mathbf{1 8}$ & $\mathbf{2 8}$ & $\mathbf{3 8}$ & $\mathbf{4 8}$ & Maxillary & Mandibular & Total \\
Males & $94(33.8 \%)$ & $77(27.7 \%)$ & $51(18.4 \%)$ & $56(20.1 \%)$ & $171(61.5 \%)$ & $107(38.5 \%)$ & $278(59.3 \%)$ \\
Females & $57(29.8 \%)$ & $50(26.2 \%)$ & $41(21.5 \%)$ & $43(22.5 \%)$ & $107(56 \%)$ & $84(44 \%)$ & $191(40.7 \%)$ \\
Total & $151(32.2 \%)$ & $127(27.1 \%)$ & $92(19.6 \%)$ & $99(21.1 \%)$ & $278(59.3 \%)$ & $191(40.7 \%)$ & 469 \\
$P$-value & $0.449^{\mathrm{NS}}$ & $0.270^{\mathrm{NS}}$ & $0.042^{*}$ & $0.062^{\mathrm{NS}}$ & $0.192^{\mathrm{NS}}$ & $0.006^{*}$ & \\
\hline
\end{tabular}

NS: $P>0.05$; Not Significant; * $P<0.05$; Significant

$P$-values were calculated using Chi Square tests 
Original Article | Radiographic evaluation of the status of third molars

(15.3\%), grooving (6.5\%), none (4.4\%), and perforation (o.6\%) (Table 4). The mesioangularly placed M3s with notching pattern of approximation to IDC followed by adjacent pattern showed the maximum distribution.

\section{Discussion}

The human evolutionary history reveals that tooth agenesis is the most common craniofacial anomaly recorded in humans and the M3s are most commonly affected (6). According to
Darwin (1981), Gregory (1922) and Hellman (1940), the M3s are decadent teeth that will become vestigial in the coming civilized human races and will be lost eventually (17). However, Nanda et al. (18) showed that the differences in the incidence of M3s agenesis are associated with underlying genetic differences.

The present study was carried out among subjects aged $25-45$ years as the age for eruption for M3s ranges from 13 to 24 years, and fewer people suffers from M3s associated problems before 24 years. The $20-25$ years

Table 3. Distribution and correlation of impacted third molars and their different patterns according to gender and diet

\begin{tabular}{|c|c|c|c|c|c|}
\hline Gender & 18 & 28 & 38 & 48 & Total \\
\hline Males & $45(14.7 \%)$ & $53(17 \cdot 3 \%)$ & $105(34.2 \%)$ & $104(33.9 \%)$ & $307(62.4 \%)$ \\
\hline Females & $36(19.5 \%)$ & $37(20 \%)$ & $57(30.8 \%)$ & $55(29.7 \%)$ & $185(37.6 \%)$ \\
\hline Total & $81(16.5 \%)$ & $90(18.3 \%)$ & $162(32.9 \%)$ & $159(32.3 \%)$ & 492 \\
\hline$P$-value & $0.040^{*}$ & $0.133^{\mathrm{NS}}$ & $0.644^{\mathrm{NS}}$ & $0.800^{\mathrm{NS}}$ & \\
\hline Diet & 18 & 28 & 38 & 48 & Total \\
\hline Vegetarian & $34(18.6 \%)$ & $39(21.3 \%)$ & $59(32.2 \%)$ & $51(27.9 \%)$ & $183(37.2 \%)$ \\
\hline Mixed & $47(15.2 \%)$ & $51(16.5 \%)$ & $103(33 \cdot 3 \%)$ & $108(35 \%)$ & $309(62.8 \%)$ \\
\hline Total & $81(16.5 \%)$ & $90(18.3 \%)$ & $162(32.9 \%)$ & $159(32.3 \%)$ & 492 \\
\hline$P$-value & $0.189^{\mathrm{NS}}$ & $0.095^{\mathrm{NS}}$ & $0.861^{\mathrm{NS}}$ & $0.464^{\mathrm{NS}}$ & \\
\hline Type of Impaction & 18 & $\mathbf{2 8}$ & 38 & 48 & Total \\
\hline Vertical & $23(28.4 \%)$ & $17(18.9 \%)$ & $23(14.2 \%)$ & $27(17 \%)$ & $90(18.3 \%)$ \\
\hline Mesioangular & $16(19.8 \%)$ & $15(16.7 \%)$ & $84(51.9 \%)$ & $89(56 \%)$ & $204(41.5 \%)$ \\
\hline Distoangular & $34(42 \%)$ & $48(53 \cdot 3 \%)$ & 37 (22.8\%) & $29(18.2 \%)$ & $148(30.1 \%)$ \\
\hline Horizontal & $1(1.2 \%)$ & $1(1.1 \%)$ & $17(10.5 \%)$ & $11(7 \%)$ & $30(6.1 \%)$ \\
\hline Buccolingual & $7(8.6 \%)$ & $9(10 \%)$ & $1(0.6 \%)$ & $1(0.6 \%)$ & $18(3.6 \%)$ \\
\hline Others & o (o\%) & o (o\%) & o (o\%) & $2(1.2 \%)$ & $2(0.4 \%)$ \\
\hline Total & $81(16.5 \%)$ & $90(18.3 \%)$ & $162(32.9 \%)$ & $159(32.3 \%)$ & 492 \\
\hline
\end{tabular}

NS: $P>0.05$; Not Significant; ${ }^{*} P<0.05$; Significant

Table 4. Distribution of different patterns of IDC relation with the roots of impacted mandibular third molars

\begin{tabular}{lccc} 
IDC relation with impacted mandibular third molars & $\mathbf{3 8}$ & $\mathbf{4 8}$ & Total \\
Adjacent & $58(35.8 \%)$ & $50(31.5 \%)$ & $108(33.6 \%)$ \\
Superimposed & $27(16.7 \%)$ & $22(13.8 \%)$ & $49(15.3 \%)$ \\
Grooving & $8(4.9 \%)$ & $13(8.2 \%)$ & $21(6.5 \%)$ \\
Notching & $61(37.7 \%)$ & $66(41.5 \%)$ & $127(39.6 \%)$ \\
Perforation & $2(1.2 \%)$ & $0(0 \%)$ & $2(0.6 \%)$ \\
None & $6(3.7 \%)$ & $8(5.0 \%)$ & $14(4.4 \%)$ \\
Total & $162(50.5 \%)$ & $159(49.5 \%)$ & 321 \\
\hline
\end{tabular}




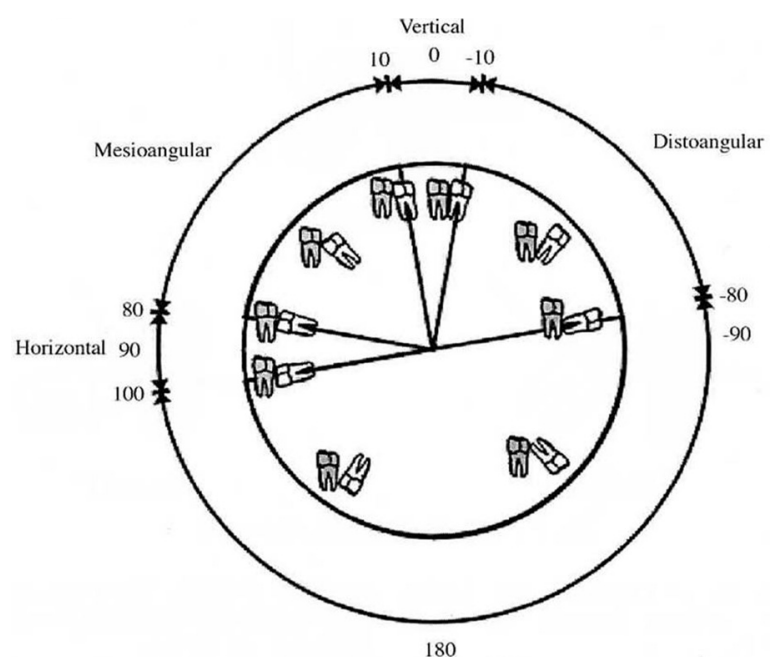

Figure 2. Winter's classification.

age group is the most suitable for studying the frequency of M3s and its impaction patterns to avoid overestimation of $\mathrm{M}_{3}$ agenesis due to unnoticed early extraction in the older group (19). Moreover, many M3s impacted teeth can change their position and erupt after 20 years with constant eruption path until the adjacent teeth contact was made (20).

In present study, the prevalence of patients with at least one M3 agenesis was found to be slightly more than that reported by John et al. (6) (26.2\%), Rozkovcova et al. (21) (22.5\%), Raloti et al. (17) (22.9\%), Banks et al. (22) (19.7\%), Nanda et al. (18) (12.7\%), and Bhutta et al. (23) (31.7\%). The prevalence of patients having all M3s present was reported to be lesser than that reported by previous studies (24-25).

The overall agenesis of total M3s was found to be more than the data reported by Sandhu et al. (4) Verma et al. (26), Upadhyaya et al. (27), Byahatti et al. (25), Saini et al. (24). The individual percentage of agenesis of 18, 28, 38 and 48 in our study was found to be somewhat different from the study by Verma et al. (26) in which it was estimated to be $11.4 \%, 12.3 \%, 4.5 \%$ and $5.5 \%$ for $18,28,38$ and 48 , respectively. The range of variation may be due to different age, gender or sampling methods considered in different studies.

In the present study, the prevalence of M3 agenesis was reported to be the highest for one M3 and the least for all four M3s, which is in accordance with the studies conducted by Sandhu et al. (4). However, this is in contrast to the studies by Banks (22), who reported the order to be 2, 1, 4 and 3, and by Hattab et al. (30), Nanda et al. (18), and Kruger et al. (28), who reported the order to be $1,2,3$ and 4 .

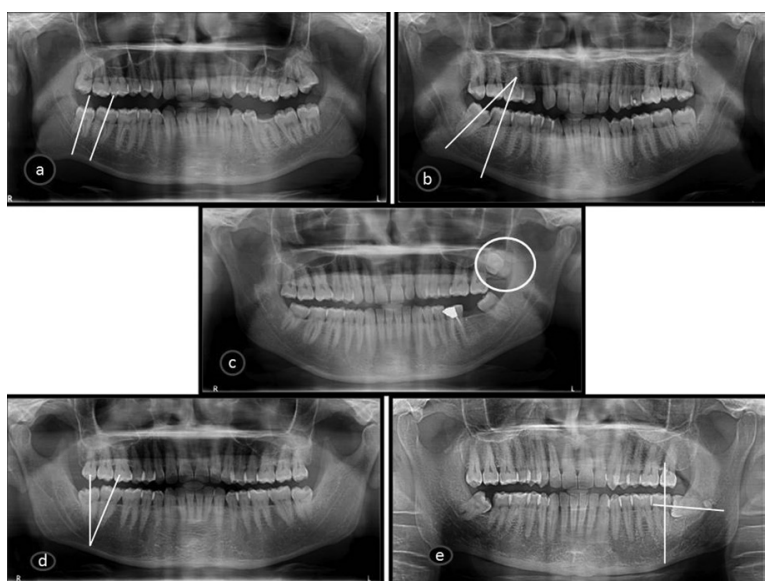

Figure 3. OPGs showing (a) Vertical Impaction 48; (b) Mesioangular Impaction 48; (c) Buccolingual Impaction 28; (d) Distoangular Impaction 48; (e) Horizontal Impaction 38.

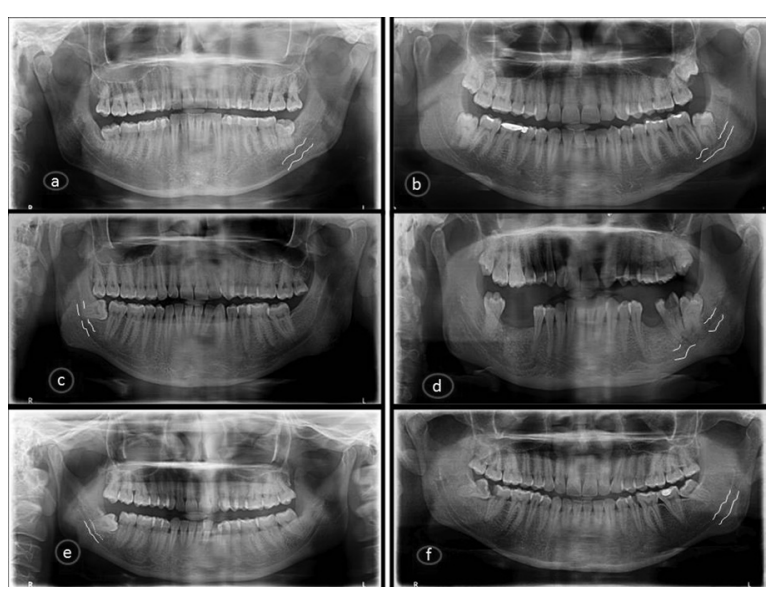

Figure 4. OPGs showing different relations of IDC with root apices of mandibular M3s: (a) Adjacent in relation to 38; (b) Notching in relation to 38; (c) Grooving in relation to 48; (d) Perforation in relation to 38 ; (e) Superimposed in relation to 48; (f) None in relation to 38.

The overall $\mathrm{M}_{3}$ agenesis in our study was found to be higher for males than for females. When the difference was analyzed statistically, the $P$-value was found to be significant in relation to 38 , but it was not significant in relation to 18 , 28 , and 48 . These findings are in accordance with Upadhyaye et al. (27) and different from those reported by Sandhu et al. (4) and Verma et al. (26). This might be attributed to the random selection of subjects and more number of male patients as compared to females. 
When comparing the number of M3s agenesis in upper and lower jaws, our results displayed more proportion in the upper jaw. These results are sporadic; a majority of authors refer about dominancy in the upper jaw when talking about the incidence of this anomaly. Similar results were obtained by Garn et al. (1), Kramer et al. (29), Hattab et al. (30), Sandhu et al. (4), and Verma et al. (26) (22.73\% and 9.55\%), John et al. (6), and Saini et al. (24). This may be due to the constantly increasing cerebration of man that enlarges his brain case at the expense of his jaws (26). The difference in maxillary and mandibular M3s agenesis, when compared between males and females statistically, was found to be significant for mandibular M3s agenesis $(P=0.006)$.

The overall agenesis of M3s on the left side was reported to be less than on the right side. When agenesis was compared between males and females for the right and left side M3s statistically, the difference was found to be significant for left side M3s $(P=0.031)$.

Due to the evolutionary process, the human jaw has shrunken, and in this process, there is insufficient space left in the dental arches to accommodate the last teeth (3). In our study, the overall impaction of M3s was reported to be $21.11 \%$. When compared between males and females, the difference was found to be significant with respect to $18(P=0.04)$.

Impaction in mandible was more common than in maxilla. This tendency of more impaction in the mandible was also expressed by the results of Shah et al. (3), Nanda et al. (18), Shetty et al. (31), and Quek et al. (32). According to Mehdizadeh et al. (33), this is because, in the lower jaw, the chances of full eruption and positional correction of M3s are very less compared to the upper jaw.

The overall impaction of M3s on the right side was reported to be less than on the left side, and the ratio of left to right side $\mathrm{M}_{3}$ impaction was 11:10, which is similar to the results reported by Mwaniki et al. (34), in which the ratio was 11:8.

The total number of impacted M3s was higher in males as compared to females, which is in contrast to the Hellman's statement, which stated that the growth of female jaws stopped just after M3s eruption begins, whereas in males, the jaw growth continues beyond the time of eruption of M3s. This difference in results might be due to the large sample of male patients as compared to females (16).
There is a direct relationship of diet and masticatory function on craniofacial growth, especially the jaws. Yamada and Kimmel's study showed that in rats consuming soft vegetarian diet, the inferior and lateral periosteal bone growth of ramus and elongation of mandibular condyle was slowed with consequent decrease in functional force application (35-36). Moreover, muscle function was found to influence the transverse growth of the skull and the dental arch width in regions with erupting molars (6). However, in our study, out of total 492 impacted M3s, 309 M3s were impacted in patients with mixed diet as compared to 183 in vegetarians. This might be attributed to the high percentage of mixed diet population in our study. When compared with the males and females statistically, the difference was found to be insignificant. Also, the most common pattern of M3s impaction is mesio-angular impaction, which is in accordance with the studies by Shah et al. (3), Hatem et al. (37), Hattab et al. (30), and Quek et al. (32). However, this finding is in contrast to studies by Padhye et al. (38), Hazza et al. (13), and Gupta et al. (16), in which the highest proportion was in the vertical position. Our finding was also in contrast to the study by Richardson, in which the highest number was in the horizontal position. This variability in the results demonstrates that the angular position of impacted M3s varies among different population groups. Mandibular-impacted M3s showed a higher frequency of mesioangular inclination than maxillary M3s. The maxillary-impacted M3s showed a higher frequency of distal inclination, which is similar to the study by Sandhu et al. (4).

The risk of neurological complications after the extraction of impacted M3s increases dramatically when there is a contact between an impacted M3 and mandibular canal. The IDC position varies with the position of apices of impacted M3s. In our study, the most common IDC relation with the root apices of impacted M3s notching and perforation was the least common. This is in accordance with the studies by Gupta et al. (16) and Hazza's et al. (13), in which the perforation was the least common type and the superimposed was the most predominant type.

In the present study, angulation-wise distribution of IDC relation in respect to impacted mandibular M3s showed maximum mesioangularly placed M3s with notching relations followed by an adjacent pattern. The 
reason might be the predominant occurrence of the mesioangular pattern in impacted mandibular M3s.

\section{Conclusion}

This study highlighted the evolutionary increasing $\mathrm{M}_{3}$ agenesis. It also highlighted the importance of diagnostic OPG for seeing the status of M3s in jaws and assessing the approximation of IDC with the root apices of mandibular-impacted M3s before any surgical intervention. Our study provides only preliminary data; therefore, further multicentered and comprehensive largesized studies are required to substantiate its usefulness. The regular monitoring of the status of M3s should become an integral part of the appropriate oral health care due to considerable differences.

\section{Acknowledgement}

None

\section{Conflict of Interest}

None

\section{Funds}

None

\section{Authors' Contribution}

Conception and design: SG

Analysis and interpretation of the data: SG

Drafting of the article: PV

Critical revision of the article for important intellectual content: SG

Final approval of the article: PV

Provision of study materials or patients: PV

Statistical expertise: PV

Administrative, technical, or logistic support: SSR

Collection and assembly of data: SSR

\section{Correspondence}

Associate Professor Dr. Pradhuman Verma MDS in Oral Medicine \& Radiology (Guru Nanak Dev Dental College, Sunam, Punjab) Post Graduate Diploma in Forensic Sci. (Punjabi University Patiala; Punjab), Department of Oral Medicine \& Radiology, Surendera Dental College \& Research Institute, H.H Gardens, Power House Road,

Sriganganagar - 335001,

Rajasthan, India

Tel: +919660127525

E-mail:pradhuman_verma@rediffmail.com

\section{References}

1. Garn SM, Lewis AB, Bonne B. Third molar formation and its development course. Angle Orthod. 1962;32:270-279.

2. Vilela EM, Vitoi PA. Study of position and eruption of lower third molars in adolescents. Rev Sul Bras Odontol. 2011;8(4):390-397.

3. Shah AP, Parekh PA. An evaluation of genesis and impaction of 3 rd molar in adolescents. Int $J$ Med Dent Sci. 2014;3(2):329-334. http://dx.doi. org/10.19056/ijmdsjssmes/2014/v3i1/80692

4. Sandhu S, Kaur T. Radiographic evaluation of the status of third molars in the AsianIndian students $J$ Oral Maxillofac Surg. 2005;63(5):640-645. http://dx.doi.org/10.1016/ j.joms.2004.12.014

5. Celikoglu M, Kamak H. Patterns of third-molar agenesis in an orthodontic patient population with different skeletal malocclusions. Angle Orthod. 2012;82(1):165-169. http://dx.doi.org/ 10.2319/041911-274.1

6. John J, Nambiar P, Mani SA, Mohamed NH, Ahmad NF, Murad NA. Third molar agenesis among children and youths from three major races of Malaysians. J Dent Sci. 2012;7(3):211217. http://dx.doi.org/10.1016/j.jds.2012.05.002

7. Ades AG, Joondeph DR, Little RM, Chapko MK. A long-term study of the relationship of third molars to changes in the mandibular dental arch. Am J Orthod Dentofac Orthop. 1990;97(4):323335. http://dx.doi.org/10.1016/o889-5406(90) 70105-L 
Original Article | Radiographic evaluation of the status of third molars

8. Ayaz H, Rehman A. Pattern of impacted mandibular third molar in patients reporting to Department of Oral and Maxillofacial Surgery, Khyber College of Dentistry, Peshawar. J Khyber Coll Dent. 2012;2(2):50-53.

9. Punjabi SK, Khoso NA, Butt AM, Channar KA. Third molar impaction: Evaluation of symptoms and pattern of impaction of mandibular third molar teeth. J Liaquat Uni Med Health Sci. 2013;12(1):26-29.

10. Howe GL. Minor oral surgery. 3rd ed. London: John Wright \& Sons. 1978;89-115. Available from: http://id.scibd.com/document/96517042/h

11. Hashemipour MA, Arashlow MT, Hanzaei FF. Incidence of impacted mandibular and maxillary third molars: A radiographic study in a Southeast Iran population. Med Oral Patol Oral Cir Bucal. 2013;18(1):40-45. http://dx.doi.org/10.4317/ medoral.18028

12. Jerjes W, El-Maayath M, Swinson B, et al. Inferior alveolar injury and surgical difficulty prediction in third molar surgery: the role of dental panoramic tomography. J Clin Dent. 2006;17(5):122-130.

13. Hazza's AM, Albashaireh ZS, Bataineh AB. The relationship of the inferior dental canal to the roots of impacted mandibular third molars in Jordanian population. $J$ Contemp Dent Pract. 2006;7(2):71-78.

14. Blaeser BF, August MA, Donoff RB, Kaban LB, Dodson TB. Panoramic radiographic risk factors for inferior alveolar nerve injury during third molar extraction. J Oral Maxillofac Surg. 2003;61(4):417-421. http://dx.doi.org/10.1053/ joms.2003.50088

15. Nakayama K, Nonoyama M, Takaki Y, Kagawa $\mathrm{T}$, Yuasa K, et al. Assessment of the relationship between impacted mandibular third molars and inferior alveolar nerve with dental 3-dimensional computed tomography. Am Assoc Oral Maxillofac Surg. 2009;67:2587-2591. http://dx.doi. org/10.1016/j.joms.2009.07.017

16. Gupta S, Bhowate RR, Nigam N, Saxena S. Evaluation of impacted mandibular third molars by panoramic radiography. ISRN Dentistry. 2011;2011:1-8 http://dx.doi.org/ $10.5402 / 2011 / 406714$
17. Raloti S, Mori R, Makwana S, Patel V, Menat A et al. Study of a relationship between agenesis and impacted third molar (Wisdom) teeth. Int $J$ Res Med. 2013;2(1):38-41.

18. Nanda RS. Agenesis of third molar in man. Am $J$ Orthod. 1954;40:698-706.

19. Schersten E, Lysell L, Rohlin M. Prevalence of impacted third molars in dental students. Swed Dent J. 1989;13(1-2):7-13.

20. Khalil AA, Abood SW, Al-Delaimi TN. The evaluation of impacted third molars using panoramic radiography. Al-Anbar Medical J. 2010;8(1):26-33. http://dx.doi. org/10.5402/2011/406714

21. Rozkovcova E, Markova M, Lanik J, Zvarova J. Agenesis of third molars in young Czech population. Prague Med Rep. 2004;105(1):3552.

22. Banks HV. Incidence of third molar development. Angle Orthod. 1934;4:223-233.

23. Bhutta N, Sadozai SK. Assessment of missing third molars with skeletal patterns. Pak Dent J. 2013;33(2):307-311.

24. Saini P, Pankaj JP, Kumar VK, Katara P. Prevalence of eruption status of third molars in college students of Bikaner. Int $\mathrm{J} \mathrm{Med} \mathrm{Sci.}$ 2014;1(2):69-74.

25. Byahatti S, Ingafou MS. Prevalence of eruption status of third molars in Libyan students. Dent Res J. 2012;9(2):152-157. http://dx.doi. org/10.4317/jced.2.e1

26. Verma P, Verma KG. Prevalence and agenesis of third molars among adolescents and young adults in Sunam City. $J$ Indian Dent Assoc. 2012;6(1):20-22.

27. Upadhyaya C, Adhikari BR, Kafle D, Humagain M. Agenesis of orthodontic patients attending Dhulikhel Hospital, Kathmandu University Hospital. Dhulikhel, Nepal. Orthod J Nepal. 2012;2(1):33-36. http://dx.doi.org/10.3126/ojn. v2i1.9292

28. Kruger E, Thomson WM, Konthasinghe P. Third molar outcomes from age 18 to 26: Findings from a population-based New Zealand longitudinal study. Oral Surg Oral Med Oral Pathol Oral Radiol Endod. 2001;92(2):150-155. http://dx. doi.org/10.1067/moe.2001.115461 
29. Kramer RM, Williams AC. The incidence of impacted teeth-a survey at Harlem hospital. Oral Surg Oral Med Oral Pathol Oral Radiol Endod. 1970;29(2):237-241. http://dx.doi.org/ 10.1016/0030-4220(70)90091-5

30. Hattab FN. Positional changes and eruption of impacted mandibular third molars in young adults: A Radiographic 4-year follow-up study. Oral Surg Oral Med Oral Pathol Oral Radiol Endod. 1997;84(6):604-608. http://dx.doi. org/10.1016/S1079-2104(97)903590

31. Shetty P, Banerjee S. Missing molars: a study on status of third molars. $J$ Pharm Biomed Sci. 2010;4(10):1-3. http://dx.doi.org/10.1016/jfct. 2010.07.039

32. Quek SL, Tay CK, Tay KH, Toh SL, Lim KC. Pattern of third molar impaction in a Singapore Chinese population: A retrospective radiographic survey. Int $J$ oral Maxillofac Surg. 2003; 32(5):548-552. http://dox.doi.org/10.1054/ ijom.2003.0413

33. Mehdizadeh M, Haghanifar S, Seyedmajidi M, Bijani A, Saufizadeh R. Radiographic evaluation of impacted third molars and their complications in a group of Iranian population. $J$ Res Pract Dent. 2014:41-11. http://dox.doi. org/10.5171/2014.486120
34. Mwaniki D, Guthua SW. Incidence of impacted third molars among dental patients in Nairobi, Kenya. Trop Dent J. 1996;19:9-17.

35. Kramer RM, Williams AC. The incidence of impacted teeth-a survey at Harlem hospital. Oral Surg Oral Med Oral Pathol Oral Radiol Endod. 1970; 29(2):237-241. http://dox.doi. org/10.1016/0030-4220(70)90091-5

36. Yamada K, Kimmel DB. The effect of dietary consistency on bone mass and turnover in the growing rat mandible. Arch Oral Biol. 1991;36(2):129-138. http://dox.doi. org/10.106/0003-9969(91)90075-6

37. Hatem M, Bugaighis I, Taher EM. Pattern of third molar impaction in Libyan population: A retrospective radiographic study. Saudi $J$ Dent Res. 2015; http://dox.doi.org/10.1016/j. sjdr.2015.04.005

38. Padhye MN, Dabir AV, Girotra CS, Pandhi VH. Pattern of mandibular third molar impaction in the Indian population: a retrospective clinicoradiographic survey. Oral Surg Oral Med Oral Pathol Oral Radiol. 2013;116(3):161-166. http:// dx.doi.org/10.1016/j.00o.2011.12.019 